\title{
Amorphized length and variability in phase-change memory line cells
}

\author{
Nafisa Noor ${ }^{*} 1, \S$, Sadid Muneer ${ }^{2, \S}$, Raihan Sayeed Khan ${ }^{3}$, Anna Gorbenko ${ }^{3}$ \\ and Helena Silva ${ }^{3}$
}

\section{Full Research Paper}

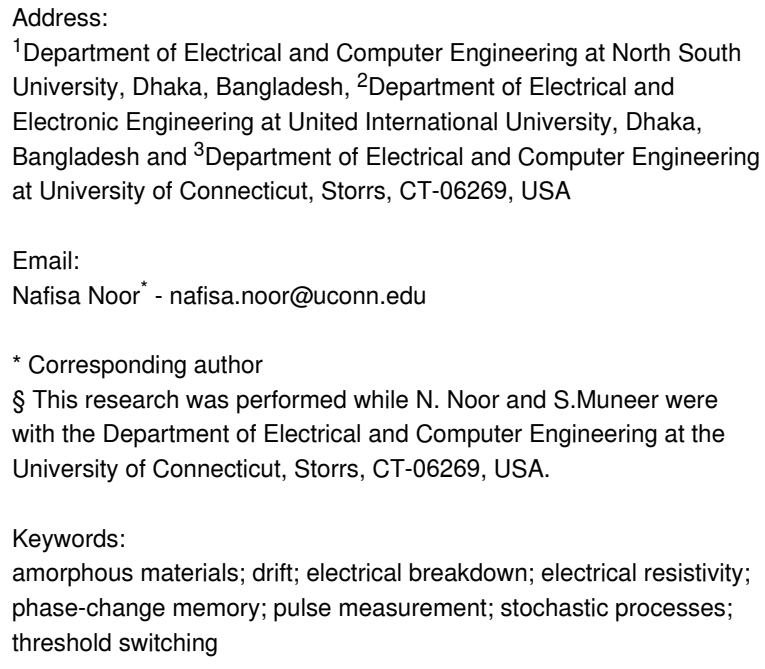

${ }^{1}$ Department of Electrical and Computer Engineering at North South University, Dhaka, Bangladesh, ${ }^{2}$ Department of Electrical and

Electronic Engineering at United International University, Dhaka, Bangladesh and ${ }^{3}$ Department of Electrical and Computer Engineering at University of Connecticut, Storrs, CT-06269, USA

Email:

Nafisa Noor* - nafisa.noor@uconn.edu

* Corresponding author

$\S$ This research was performed while N. Noor and S.Muneer were with the Department of Electrical and Computer Engineering at the University of Connecticut, Storrs, CT-06269, USA.

Keywords:

amorphous materials; drift; electrical breakdown; electrical resistivity; phase-change memory; pulse measurement; stochastic processes; threshold switching

\author{
Beilstein J. Nanotechnol. 2020, 11, 1644-1654 \\ https://doi.org/10.3762/bjnano.11.147 \\ Received: 07 May 2020 \\ Accepted: 05 October 2020 \\ Published: 29 October 2020 \\ Associate Editor: T. Glatzel \\ (C) 2020 Noor et al.; licensee Beilstein-Institut. \\ License and terms: see end of document.
}

\begin{abstract}
The dimensions of amorphized regions in phase-change memory cells are critical parameters to design devices for different applications. However, these dimensions are difficult to be determined by direct imaging. In this work, the length of amorphized regions in multiple identical $\mathrm{Ge}_{2} \mathrm{Sb}_{2} \mathrm{Te}_{5}$ (GST) line cells was extracted from electrical measurements. After each cell was programmed to an amorphous state, a sequence of increasing-amplitude post-reset voltage pulses separated by low-amplitude read DC sweeps was applied. When a post-reset voltage pulse with sufficient amplitude was applied to a given cell, the measured current and the postpulse resistance increased drastically, indicating that the cell re-amorphized after threshold switching, melting, and quenching. The amorphized length was calculated using the measured voltage at which the threshold switching occurred and the expected drifted threshold field at that time. The measured threshold voltage values and, hence, the extracted amorphized length, generally increase linearly with the programmed resistance levels. However, significant variability arises from the intrinsically unique crystallization and amorphization processes in these devices. For example, cells programmed to an amorphous resistance of approx. $50 \mathrm{M} \Omega$ show threshold voltage values of 5.5-7.5 V, corresponding to amorphized length values of 290-395 nm. This unpredictable programming feature in phase-change memory devices can be utilized in hardware security applications.
\end{abstract}




\section{Introduction}

Phase-change memory (PCM) is an emerging non-volatile memory technology with high endurance, high speed, and good scalability. PCM relies on the change in phase of a nanoscale volume of a chalcogenide material sandwiched between two electrodes. The phase of the material can be switched between the high-resistivity state (amorphous or reset) and the low-resistivity (crystalline or set) state by appropriate electrical pulses. The amorphization (or reset) process in PCM is achieved with a short and abrupt electrical pulse, which melt-quenches the active region [1]. PCM nanodevices exhibit significant cell-tocell and cycle-to-cycle programming variability due to the intrinsic randomness in the crystallization and amorphization processes, in addition to any variation in the fabrication process. This probabilistic programming feature in PCM has been recently considered for several applications in hardware security, such as physical unclonable functions or true random number generators [2-7]. It is critical to characterize the physical factors that contribute to the observed variability for conclusive understanding and proper utilization of this feature for these hardware security primitives. An essential physical parameter that contributes to the programming variability is the random location and dimensions of different phases formed in the cell. The amorphous and crystalline regions in PCM devices can be distinguished by transmission electron microscopy (TEM) imaging [8]. However, this is a difficult and time-consuming process, and the sample preparation and imaging processes themselves may disturb the state of the material $[9,10]$. Hence, TEM becomes impractical for variability analysis using a large number of devices.

In this study, the length values of the amorphized regions are calculated from electrical measurements on $25 \mathrm{Ge}_{2} \mathrm{Sb}_{2} \mathrm{Te}_{5}$ (GST-225) PCM line cells of very similar dimensions. The crystalline PCM line cells were first amorphized with one or more reset pulses. Then, a sequence of post-reset pulses was applied with gradually increasing amplitudes. The cells were read after each pulse. When the applied post-reset pulse amplitude was high enough, a significant increase in the measured current and post-pulse cell resistance was observed. This indicated a re-amorphization after threshold switching, melting, and subsequent quenching, as inferred from the measurements and circuit simulation results obtained from the "simulation program with integrated circuit emphasis" (SPICE). The measured threshold voltage, and the drifted threshold field at that time are used to extract the amorphized length (Figure 1).

\section{A literature review of threshold switching in PCM}

Threshold switching is a sudden and reversible physical process in amorphous chalcogenides, which is accompanied by a sharp

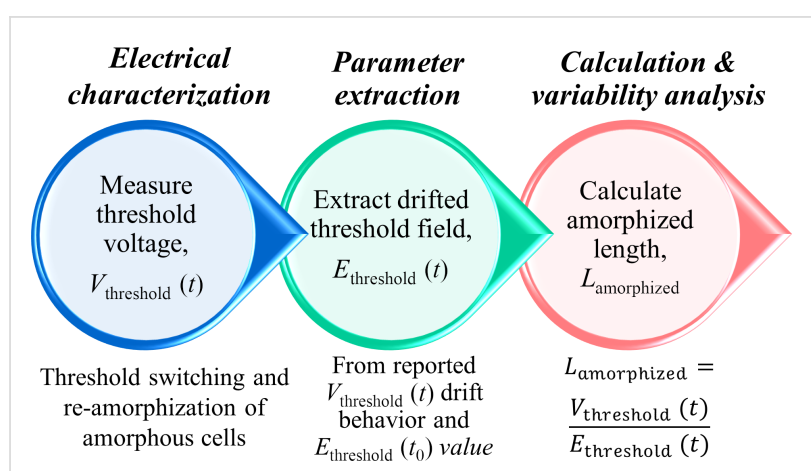

Figure 1: Schematic of the procedure used in this work for extraction of amorphized length in phase-change memory line cells.

decrease in resistance. Various models were presented in the 1970s to explain the threshold switching process. Some of these models indicated pure thermal effects [11], whereas some referred to pure electrical effects [12]. Others pointed to a combination of both [13]. The argument was settled for decades with the dominance of the electrical model. However, it was re-ignited in the last decade by the difficulties in understanding threshold switching in PCM cells at the nanoscale. Among several new explanations based on electrical [14-18] and thermally assisted [19] effects, the electrical models are again prevailing, even though the specific mechanisms are expected to depend on the device geometry and dimensions [19].

According to the current understanding, threshold switching is initiated by an electrical breakdown due to impact ionization, a purely electrical effect. The following sharp increase in current is ascribed to thermal runaway (i.e., a decrease in resistivity with increasing temperature that leads to further heating [17]). In this work, we use this model to interpret our measurement results.

Krebs et al. measured a threshold field of $56 \mathrm{~V} / \mu \mathrm{m}$ for as-deposited GST amorphous bridge cells by measuring the threshold voltage values of various cells of known dimensions. They concluded that the threshold field is a material-dependent physical parameter, whereas the specific threshold voltage depends on the device geometry [17]. As-deposited amorphous cells of known dimensions were used in the measurements, instead of melt-quenched cells, to avoid the difficulty in determining the dimensions of the amorphized regions. However, the drift time since deposition, which is a critical parameter, is difficult to be extracted. Since the threshold voltage, $V_{\text {threshold }}(t)$, drifts upward in time [20], an effective threshold field, $E_{\text {threshold }}(t)$, is also expected to drift similarly, while the amorphized length, $L_{\text {amorphized }}$, is expected to remain the same over time, despite structural relaxation [21] or other physical pro- 
cesses that may occur in the amorphous volume below the glass transition. The relation between $V_{\text {threshold }}(t), E_{\text {threshold }}(t)$, and $L_{\text {amorphized }}$ is given by:

$$
E_{\text {threshold }}(t)=\frac{V_{\text {threshold }}(t)}{L_{\text {amorphized }}} \text {. }
$$

Jeyasingh et al. measured a threshold field of $14 \mathrm{~V} / \mu \mathrm{m}$ in meltquenched GST devices [22]. Based on an elapsed time after amorphization of $100 \mu \mathrm{s}, t_{0}$, (from another relevant work of the same group [23]) and the threshold field at $t_{0}, E_{\text {threshold }}\left(t_{0}\right)$, it is possible to extract the threshold field, $E_{\text {threshold }}(t)$, at the elapsed time between amorphization and the time, $t$, when $V_{\text {threshold }}(t)$ was measured, using the logarithmic trend of threshold voltage drift and the room-temperature threshold voltage drift coefficient, $\gamma=0.02$, reported by Karpov et al. [20]:

$$
\begin{aligned}
& \frac{V_{\text {threshold }}(t)-V_{\text {threshold }}\left(t_{0}\right)}{V_{\text {threshold }}\left(t_{0}\right)}=\gamma \ln \left(\frac{t}{t_{0}}\right), \\
& \frac{E_{\text {threshold }}(t)-E_{\text {threshold }}\left(t_{0}\right)}{E_{\text {threshold }}\left(t_{0}\right)}=\gamma \ln \left(\frac{t}{t_{0}}\right) .
\end{aligned}
$$

In this work, we have used a value of $E_{\text {threshold }}\left(t_{0}\right)=14 \mathrm{~V} / \mu \mathrm{m}$, calculated by Jeyasingh et al. at $t_{0} \approx 100 \mu$ s after amorphization for melt-quenched amorphous line cells, to obtain $E_{\text {threshold }}(t)$ at different measured time values, $t$ on different cells programmed to a similar amorphous resistance. Equation 3 and $\gamma=0.02$ were used to calculate $L_{\text {amorphized }}$ and the associated variability. It is important to note that the term "electrical breakdown" here refers to the reversible threshold-switching process and not to the permanent and detrimental electrical breakdown failure that occurs in any dielectric material.

\section{Experimental}

The patterned GST-225 line cells used for this study were deposited on silicon dioxide $\left(\mathrm{SiO}_{2}\right)$, had bottom metal contact pads (tungsten with Ti/TiN liner), and were capped by silicon nitride [24]. All cells were approx. $130 \mathrm{~nm}$ in width, $W_{\mathrm{GST}}$, approx. $470 \mathrm{~nm}$ in length between the metal contacts, $L_{\mathrm{GST}}$, and approx. $50 \mathrm{~nm}$ in thickness, $t_{\mathrm{GST}}$ (SEM image in inset of Figure $2 \mathrm{a}$ ). The as-fabricated cells were annealed in a Janis ST-500-UHT probe station at a pressure of approx. 1 mTorr at a temperature of $675 \mathrm{~K}$ for $10 \mathrm{~min}$ to reach the crystalline phase (annealing profile shown in Figure 2a).

The electrical measurements were performed at room temperature. Electrical pulses, generated by an arbitrary function generator (Tektronix AFG 3102), were applied to the cells; a series load resistor of $5.1 \mathrm{k} \Omega$ was used to limit the current. The experimental circuit schematic is shown in Figure 2b. The experimental circuit was terminated through a digital oscilloscope (Tektronix DPO 4104) using two termination resistors of $50 \Omega$ connected to the channels 3 and 4 . The applied voltage was monitored with the channel 1 of the oscilloscope and the voltage across the parallel combination of two $50 \Omega$ resistors was monitored with channels 3 and 4 to extract the current through the cell. A semiconductor parameter analyzer (Agilent 4156C) was used for low-voltage read operations with a DC voltage sweep between -0.1 and $+0.1 \mathrm{~V}$ for all resistance levels. A relay circuit, controlled by an Arduino Mega 2560 card, was used to switch between the reading and programming sequences of the measurements.

Twenty-five identical crystalline line cells with similar initial crystalline resistance values $\left(R_{\text {crystalline }}\right)$ were amorphized to a similar programmed resistance level $\left(R_{\text {programmed }}\right)$ of
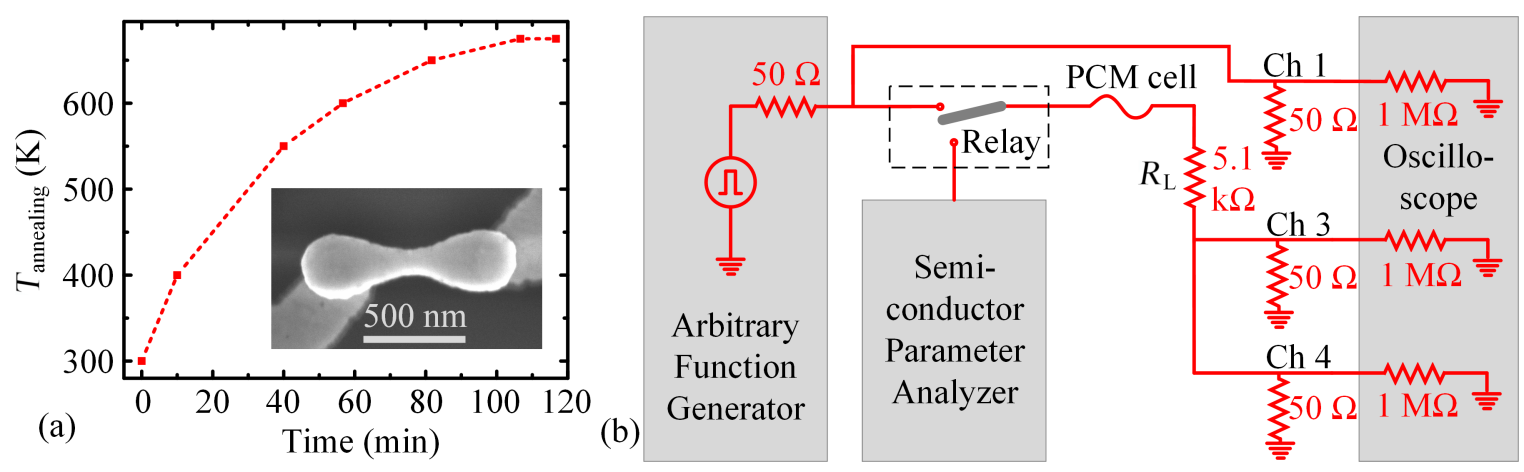

Figure 2: (a) Temperature profile used for annealing the as-fabricated amorphous devices to the crystalline phase, with a constant temperature of $675 \mathrm{~K}$ for the last $10 \mathrm{~min}$. Inset shows the SEM image of an untested annealed GST line cell, with metal-to-metal $L_{\mathrm{GST}} \approx 470 \mathrm{~nm}, W_{\mathrm{GST}} \approx 130 \mathrm{~nm}$, and $t_{\mathrm{GST}} \approx 50 \mathrm{~nm}$. (b) Electrical measurement setup. 
approx. $10^{7} \Omega$ with a comparatively narrow distribution, so that the variations in the initial $R_{\text {programmed }}$ value do not greatly affect the extraction of $L_{\text {amorphized. Table } 1 \text { shows the statistical }}$ distributions of the $R_{\text {crystalline }}$ and $R_{\text {programmed }}$ values for the 25 measured GST cells.

Table 1: Statistical distribution of cell resistance values. Minimum, maximum, and median of the crystalline and programmed resistance values ( $R_{\text {crystalline }}$ and $R_{\text {programmed }}$ ) of the 25 measured GST cells $\left(L_{\mathrm{GST}} \approx 470 \mathrm{~nm}, W_{\mathrm{GST}} \approx 130 \mathrm{~nm}\right.$, and $\left.t_{\mathrm{GST}} \approx 50 \mathrm{~nm}\right)$.

\begin{tabular}{llll}
$\begin{array}{l}\text { Cell } \\
\text { resistance }\end{array}$ & $\begin{array}{l}\text { Minimum } \\
\text { resistance }\end{array}$ & $\begin{array}{l}\text { Maximum } \\
\text { resistance }\end{array}$ & Median \\
\hline$R_{\text {crystalline }}$ & $267 \Omega$ & $3162 \Omega$ & $522 \Omega$ \\
$R_{\text {programmed }}$ & $8 \mathrm{M} \Omega$ & $65 \mathrm{M} \Omega$ & $28 \mathrm{M} \Omega$
\end{tabular}

Due to intrinsic programming variability and process variations observed from cell to cell, the number and the amplitude of the applied voltage pulses required to reach $R_{\text {programmed values of }}$ approx. $10^{7} \Omega$ varied [7]. The number of pulses varied between one and ten and the amplitude varied between 2.0 and $2.5 \mathrm{~V}$. These reset pulses were applied with gradually increasing amplitude, in increments of $0.1 \mathrm{~V}$. All amorphization voltage pulses were rectangular with a duration, $t_{\text {duration }}$ of approx. $200 \mathrm{~ns}$ and rise and fall time values, $t_{\text {rise }}=t_{\text {fall }}$, of approx. $25 \mathrm{~ns}$. Once the cells reached this initial reset condition, a sequence of rectangular "post-reset pulses", with gradually increasing amplitudes ( 0.4 to $10.0 \mathrm{~V}$ with $0.1 \mathrm{~V}$ increment), and the same $t_{\text {duration }}, t_{\text {rise }}$, and $t_{\text {fall }}$ values as used in the initial reset step were applied. Low-voltage DC sweep read operations were performed before and after each applied pulse. Figure 3 shows the schematic of the measurement sequences.

\section{Results and Discussion Measurements of the re-amorphization of a single wire}

An example of the re-amorphization procedure on an initially amorphized cell is shown in Figure 4 a, with $R_{\text {programmed }}$ plotted as a function of the applied voltage at channel 1, $V_{\text {ch1 }}=V_{\text {post-reset }}$. This cell was initially amorphized at 7.5 $\mathrm{M} \Omega$, with a certain amorphized length, $L_{\text {amorphized(1). A schematic of }}$ the possible phase distribution in the cell after the initial reset is shown in Figure 5a. The amorphous cell started to show the usual upward resistance drift [25], which was unaffected by the early lower $V_{\text {post-reset }}$ pulses. After a $V_{\text {post-reset }}$ of $1.9 \mathrm{~V}$ was applied, $R_{\text {programmed }}$ drastically increased from the drifted amorphous resistance value of $10.55 \mathrm{M} \Omega$ to $48.05 \mathrm{M} \Omega$ (Figure $4 \mathrm{a}$ ). The measured voltage at the channel 3 and 4 termination resistors, $V_{\mathrm{ch} 3,4}$ showed a sudden overshoot (green dotted line, Figure $4 \mathrm{~b}, 2$ nd row). This $V_{\operatorname{ch} 3,4}$ amplitude was significantly higher than the barely noticeable $V_{\operatorname{ch} 3,4}$ magnitude for all lower $V_{\text {post-reset }}$ amplitudes. An example of $V_{\operatorname{ch} 3,4}$ for $V_{\text {post-reset }}$ of $1 \mathrm{~V}$ is plotted in Figure $4 \mathrm{~b}$ to show the difference (2nd row, blue dashed line). Even though we monitored all waveforms, we only recorded a few to avoid additional time to elapse between the amorphization and threshold switching.

The pulse amplitude of $1.9 \mathrm{~V}$ caused a threshold switching, by means of an electrical breakdown of the previously existing insulating amorphous region of length $L_{\text {amorphized(1). Therefore, }}$ $1.9 \mathrm{~V}$ is the threshold voltage, $V_{\text {threshold(1) }}$, for the breakdown of length $L_{\text {amorphized(1) }}$. The increased amorphous resistance indicates a larger effective length of the new amorphous region, $L_{\text {amorphized(2) }}$ (Figure $5 \mathrm{~b}$ ), even though any voids formed would

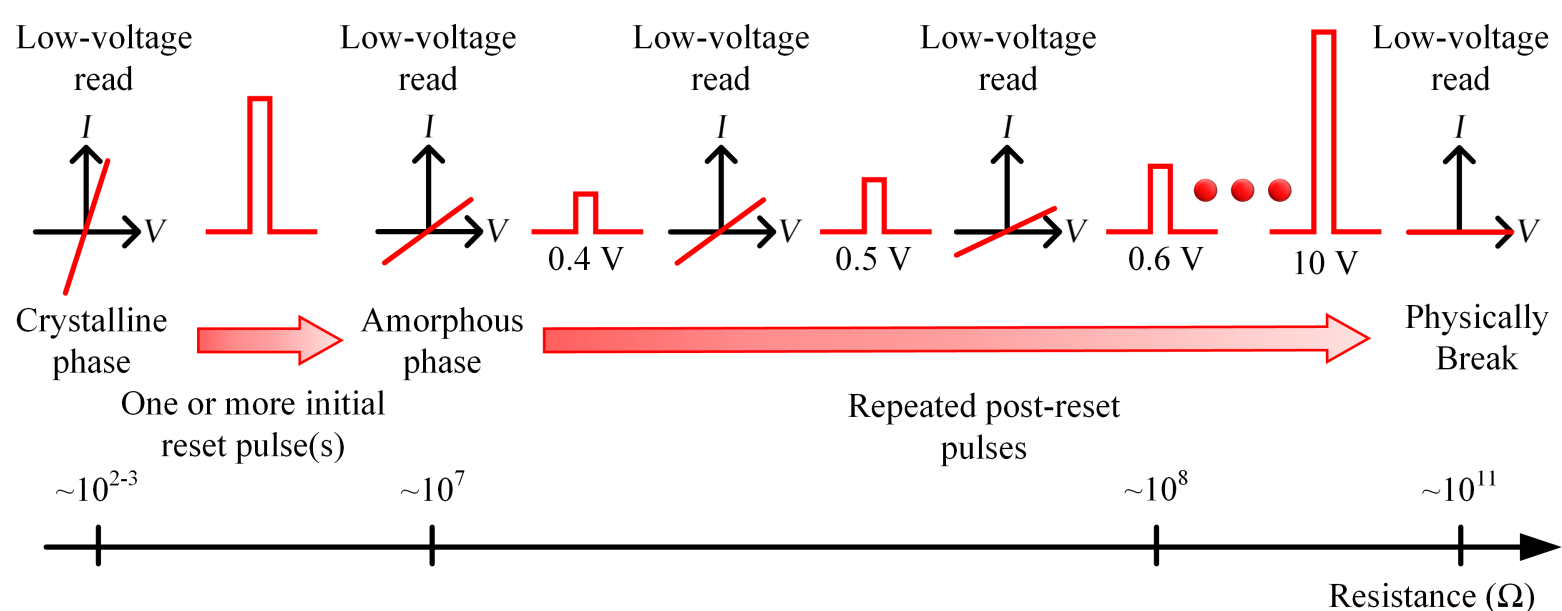

Figure 3: Schematic of the measurement sequence. One or more pulses were applied to initially reset the crystalline cells. Then, a sequence of pulses with increasing amplitude (from 0.4 to $10 \mathrm{~V}$ in $0.1 \mathrm{~V}$ increment) were applied until further re-amorphization. Eventually, physical breaking occurred with loss of electrical connection. Low-voltage read operations were performed before and after each applied pulse. 

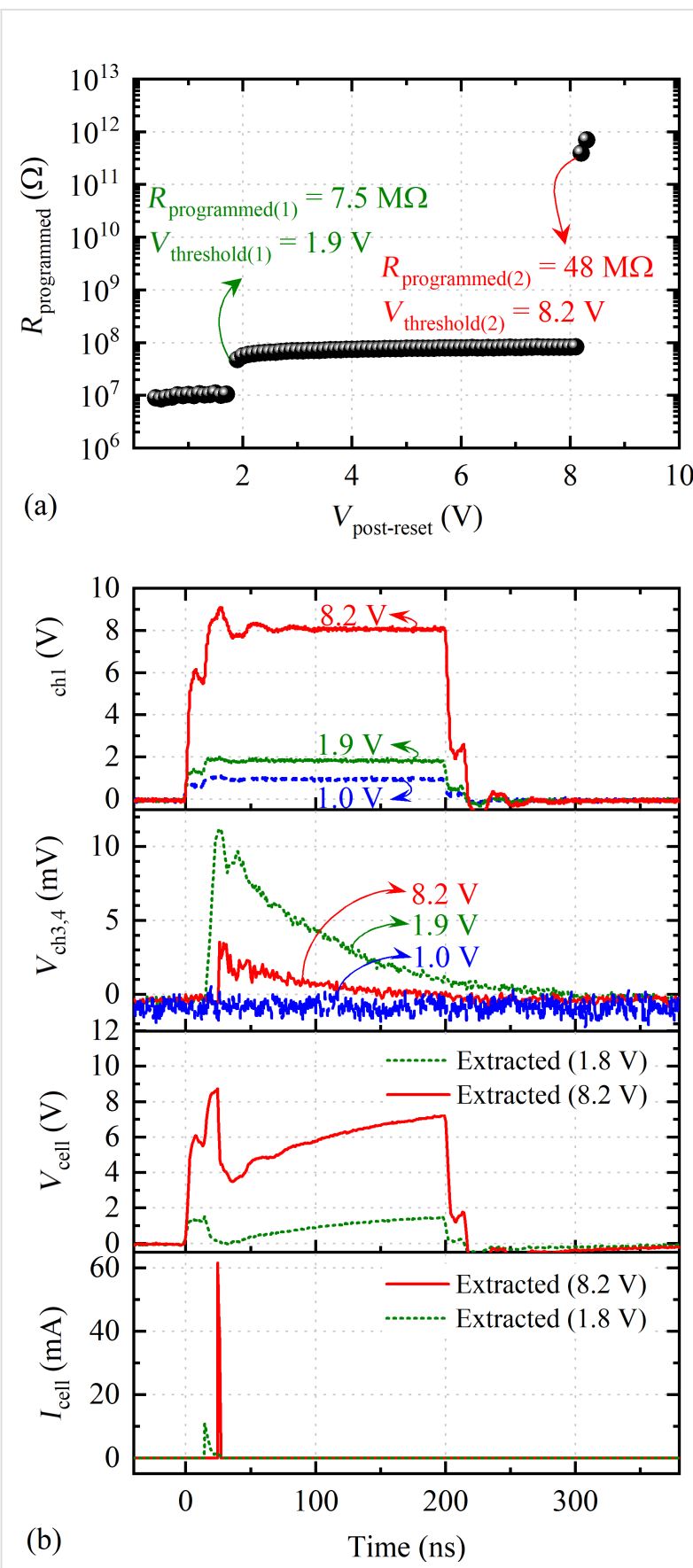

Figure 4: Repeated post-reset pulses of $200 \mathrm{~ns}$ duration and 0.4 to $10.0 \mathrm{~V}$ amplitude (with an increment of $0.1 \mathrm{~V}$ ) applied to an amorphous cell with $L_{\mathrm{GST}} \approx 470 \mathrm{~nm}, W_{\mathrm{GST}} \approx 130 \mathrm{~nm}$, and $t_{\mathrm{GST}} \approx 50 \mathrm{~nm}$, initially programmed to approx. $7.5 \mathrm{M} \Omega$. (a) Evolution of $R_{\text {programmed }}$ as a function of the post-reset pulse amplitude ( $\left.V_{\text {post-reset }}\right)$. (b) 1 st and 2nd rows: example waveforms of applied voltage at channel $1\left(V_{\text {ch1 }}\right)$ and measured voltage at channel $3,4\left(V_{\mathrm{ch} 3,4}\right)$ during an unsuccessful re-amorphization (blue dashed line), a successful re-amorphization at $V_{\text {post-reset }}$ of $1.9 \mathrm{~V}$ (green dotted line), and a breaking episode when electrical connections are lost at $V_{\text {post-reset }}$ of $8.2 \mathrm{~V}$ (red solid line). 3rd and 4th rows: These voltage waveforms for $V_{\text {post-reset }}$ of 1.9 and $8.2 \mathrm{~V}$ are input in the SPICE circuit simulations and the resulting cell voltage $\left(V_{\text {cell }}\right)$ and current $\left(I_{\text {cell }}\right)$ are extracted by modeling the experimental setup circuitry.

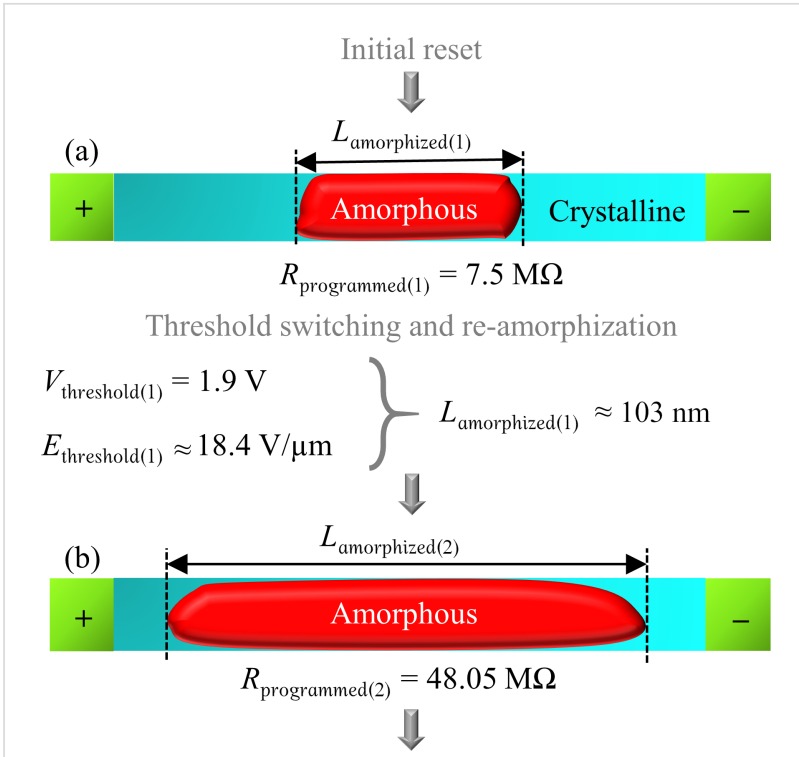

Threshold switching, re-amorphization, and physical breaking with loss of electrical connection due to voids

$$
\left.\begin{array}{l}
V_{\text {threshold(2) }}=8.2 \mathrm{~V} \\
E_{\text {threshold (2) }} \approx 18.7 \mathrm{~V} / \mu \mathrm{m}
\end{array}\right\} L_{\text {amorphized(2) }} \approx 438 \mathrm{~nm}
$$

(c)

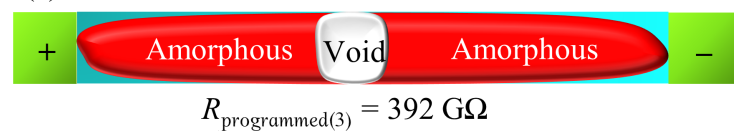

Figure 5: Schematic illustration of the calculation of the amorphized length for two post-reset re-amorphization episodes shown in Figure 4: (a) after initial reset, (b) after first re-amorphization at $V_{\text {threshold(1) }}$ of $1.9 \mathrm{~V},(\mathrm{c})$ after a second re-amorphization and physical breaking with loss of electrical connection at $V_{\text {threshold(2) }}$ of $8.2 \mathrm{~V}$. Threshold voltage values indicate the voltage at which the already existing amorphous region experienced electrical breakdown during threshold switching.

also alter the overall cell resistance. The cell resistance, again, started to drift upward and stayed unaffected by the next few post-reset pulses, until the next threshold switching event at $V_{\text {threshold(2) }}$ of $8.2 \mathrm{~V}$ of the amorphized region of length $L_{\text {amorphized(2) }}$. At this point, the wire itself physically broke and the electrical connection was lost, possibly due to void formation in the middle of the cell (Figure 5c).

\section{Cell voltage and current extraction obtained via circuit simulation}

A SPICE simulation was performed to extract the cell voltage and current ( $V_{\text {cell }}$ and $\left.I_{\text {cell }}\right)$ by inputting $V_{\text {ch1 }}$ and $V_{\operatorname{ch} 3,4}$ as the voltage sources. Figure 6a illustrates the approximate circuit model of the experimental setup (shown in Figure 2b) with the following components: channel 1 with a termination resistance of $R_{\mathrm{ch} 1}=50 \Omega$, a coaxial cable to channel 1 termination with a capacitance of $C_{\mathrm{ch} 1}=110 \mathrm{pF}$, a probe arm to the load resistor with a capacitance of $C_{\text {load }}=20 \mathrm{pF}$, a load resistance, $R_{\text {load }}$, of 


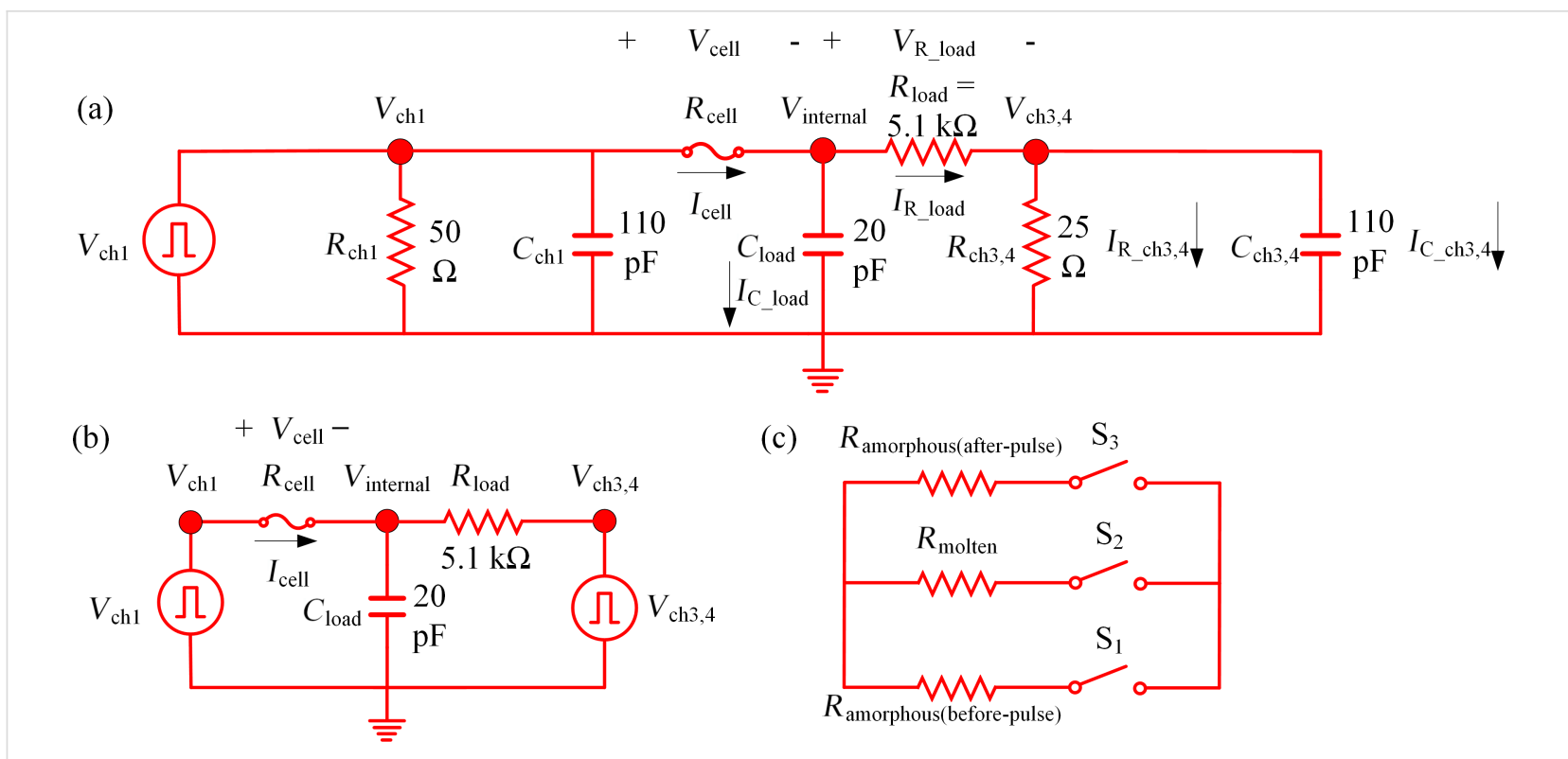

Figure 6: (a) Approximate circuit model of an experimental setup with measured parasitic capacitance and resistance values. (b) Simplified circuit model simulated in SPICE with the measured $V_{\mathrm{ch} 1}$ and $V_{\mathrm{ch} 3,4}$ waveforms. (c) Modeling of GST resistance switching with three switches in SPICE.

$5.1 \mathrm{k} \Omega$. In addition, the channel 3,4 has a termination resistance in parallel of $R_{\mathrm{ch} 3,4}=50 \| 50 \Omega=25 \Omega$ and the capacitance value of the coaxial cable to the combined terminations of the channels 3,4 is $C_{\mathrm{ch} 3,4}=110 \mathrm{pF}$. The cell resistance values, $R_{\text {cell }}$, used for the SPICE simulations are listed in Table 2.

Figure $6 \mathrm{~b}$ shows the simplified circuit model in which the parasitic capacitances and termination resistances for both channel 1 and channel 3,4 are already taken into account with the measured $V_{\mathrm{ch} 1}$ and $V_{\mathrm{ch} 3,4} \cdot R_{\text {cell }}$ is switched between the measured amorphous resistance before pulse, $R_{\text {amorphous(before-pulse), the resistance of the molten state, }}$ $R_{\text {molten, of }} 140 \Omega$, and the measured amorphous resistance after

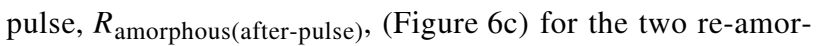

phization events shown in Figure 4. The $R_{\text {molten }}$ value is assumed to be $140 \Omega$ for all simulations, which is slightly less than the $R_{\text {crystalline value, since melting incorporates a drop in }}$ the GST resistivity [26]. Table 2 lists these different resistance values used for the circuit simulations.

Melting and re-amorphization of a GST cell is simulated with three switches $\mathrm{S}_{1}, \mathrm{~S}_{2}$, and $\mathrm{S}_{3}$ that sequentially turn on and off to include the appropriate $R_{\text {cell }}$ (Figure 6c). For both re-amorphization cases, the melting is assumed to take place when $V_{\operatorname{ch} 3,4}$ starts to rise and the re-amorphization is assumed to take place right after the peak of $V_{\operatorname{ch} 3,4}$. Table 3 lists the melting and re-amorphization instances for the two re-amorphization events used in simulations.

Table 2: Cell resistance values, $R_{\text {cell }}$, used for the two re-amorphization events in the simulations.

\begin{tabular}{llll} 
Re-amorphization events & $R_{\text {amorphous(before-pulse) }}(\mathrm{M} \Omega)$ & $R_{\text {molten }}(\Omega)$ & $R_{\text {amorphous(after-pulse) }}(\mathrm{M} \Omega)$ \\
\hline 1st re-amorphization (1.9 V) & 10.55 & 140 & 48.05 \\
2nd re-amorphization (8.2 V) & 82.66 & 140 & 392656.81
\end{tabular}

Table 3: Melting and re-amorphization instances (i.e., the switching time values used for two re-amorphization events in simulations).

\begin{tabular}{lll} 
Re-amorphization events & Melting instance (ns) & Re-amorphization instance (ns) \\
\hline 1st re-amorphization (1.9 V) & 14 & 28 \\
2nd re-amorphization (8.2 V) & 24 & 26
\end{tabular}


At the starting of the simulation, $\mathrm{S}_{1}$ is closed while $\mathrm{S}_{2}$ and $\mathrm{S}_{3}$ are kept open to use $R_{\text {amorphous(before-pulse) }}$ as the starting $R_{\text {cell }}$. During melting, $R_{\text {cell }}$ is switched from $R_{\text {amorphous(before-pulse) }}$ to $R_{\text {molten }}$ by opening $\mathrm{S}_{1}$ and closing $\mathrm{S}_{2}$, with $\mathrm{S}_{3}$ open. For re-amorphization, $R_{\text {cell }}$ is switched from $R_{\text {molten }}$ to $R_{\text {amorphous(after-pulse) }}$ by opening $\mathrm{S}_{2}$ and closing $\mathrm{S}_{3}$, with $\mathrm{S}_{1}$ open.

For both re-amorphization events, $V_{\text {cell }} \approx V_{\text {ch1 }}$ at the beginning, when $R_{\text {cell }} \approx R_{\text {amorphous(before-pulse), since } R_{\text {amorphous(before-pulse) }}}$ $\gg R_{\text {load }}$ and most of the applied $V_{\text {ch1 }}$ voltage drops across the cell. When the melting occurs, $V_{\text {cell }}$ decreases and $I_{\text {cell }}$ increases sharply, since $R_{\text {molten }} \ll R_{\text {load }}$. When the quenching occurs, $V_{\text {cell }}$ increases slowly again, since $R_{\text {amorphous(after-pulse) }}$ $\gg R_{\text {load }}$, and $I_{\text {cell }}$ decreases sharply due to the amorphization (Figure 4a, 3rd and 4th rows).

We note that $I_{\text {cell }}$ for each of the re-amorphization events consists of a very sharp triangular current pulse (of approx. $15 \mathrm{~ns}$ duration and approx. $11 \mathrm{~mA}$ amplitude for the $1 \mathrm{st}$ re-amorphization and approx. $3 \mathrm{~ns}$ duration and approx. $62 \mathrm{~mA}$ amplitude for the 2nd event) that occurs during the rising edge of the $V_{\mathrm{ch} 1}$. The very sharp rising edges of $I_{\text {cell }}$ for the two re-amorphization events can be attributed to the additional capacitive current contributions due to the parasitic capacitances present in the system and to the thermal runaway of the amorphous GST, which also lead to a quick rise of the cell temperature and produce enough Joule heating to induce melting of the material [27]. The sharp falling edges of $I_{\text {cell }}$ for the two re-amorphization events due to the discharge of parasitic capacitance can initiate quenching and block the conduction path resulting in re-amorphization [28].

The relation between the measured voltage values, $V_{\text {ch1 }}$ and $V_{\mathrm{ch} 3,4}$, and the extracted parameters, $V_{\text {cell }}$ and $I_{\text {cell }}$, can be found using the Kirchhoff's laws:

$$
\begin{gathered}
V_{\text {cell }}=V_{\text {ch } 1}-V_{\text {internal }}=V_{\mathrm{ch} 1}-V_{\mathrm{R}_{\text {load }}}-V_{\mathrm{ch} 3,4}, \\
I_{\text {cell }}=I_{C_{\text {load }}}+I_{R_{\text {load }}}=I_{C_{\text {load }}}+I_{R_{\mathrm{ch} 3,4}}+I_{C_{\mathrm{ch} 3,4}}, \\
I_{C_{\text {load }}}=C_{\text {load }}\left(\frac{\mathrm{d} V_{C_{\text {load }}}}{\mathrm{d} t}\right), \\
I_{C_{\mathrm{ch} 3,4}}=C_{\mathrm{ch} 3,4}\left(\frac{\left.\mathrm{d} V_{C_{\mathrm{ch} 3,4}}^{\mathrm{d} t}\right) .}{}\right.
\end{gathered}
$$

\section{Measurements of the re-amorphization of twenty-five wires}

We repeated the re-amorphization study on 25 cells and measured $V_{\text {threshold }}(t)$ values. The extrapolated $E_{\text {threshold }}(t)$ (Figure 7a) and the measured $V_{\text {threshold }}(t)$ (Figure 7b), both at a certain time $t$, which is different for different measured cells, are used to calculate $L_{\text {amorphized (Figure 7c) using Equa- }}$ tion 1. Since $L_{\text {amorphized }}$ remains the same for a given amorphized region, it is only important to consistently extrapolate $E_{\text {threshold }}(t)$ at the time $t$ when we measure $V_{\text {threshold }}(t)$. In Figure $7 \mathrm{~b}$, we plotted $V_{\text {threshold }}(t)$ as a function of the programmed resistance values measured at $10 \mathrm{~s}$ after amorphization $\left(R_{\text {programmed }}(10 \mathrm{~s})\right)$. Cells with higher $R_{\text {programmed }}$ values (17 out of 25 cells) physically broke after the first amorphization (i.e., initial reset) without any intermediate re-amorphization episode and are plotted as spheres in Figure 7b. Cells that experienced one or more re-amorphization episode(s) are plotted as stars connected with dotted lines in Figure 7b. We observed a linear relation between the measured $V_{\text {threshold }}(t)$ and $R_{\text {programmed }}$ (Figure 7b), which in turn is linearly related with the calculated $L_{\text {amorphized }}$ with a moderate degree of variability (Figure 7c).

There was a cell-to-cell variability in the measured $V_{\text {threshold }}(t)$

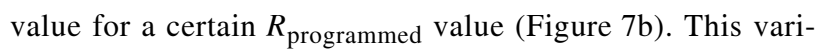
ability is also propagated to the zero-intercept fitted expression for $L_{\text {amorphized: }}$

$$
\begin{gathered}
V_{\text {threshold }}=R_{\text {programmed }} \times(1.29 \pm 0.04) \frac{\mathrm{V}}{10 \mathrm{M} \Omega}, \\
L_{\text {amorphized }}=R_{\text {programmed }} \times(68.98 \pm 1.94) \frac{\mathrm{nm}}{10 \mathrm{M} \Omega} .
\end{gathered}
$$

Equation 8 and Equation 9, the zero-intercept linear fits of the data (Figure $7 \mathrm{~b}$ and Figure 7c), show that for an amorphous region programmed to $10 \mathrm{M} \Omega$, a $V_{\text {threshold }}$ of $1.29 \pm 0.04 \mathrm{~V}$ is required for threshold switching, indicating an $L_{\text {amorphized }}$ of $68.98 \pm 1.94 \mathrm{~nm}$. The loss of electrical connection in the wire was confirmed by post-pulse DC $I-V$ characteristics and SEM imaging performed after the electrical characterization (Figure 8).

Besides process variations, these variations observed in $V_{\text {threshold }}(t)$ and $L_{\text {amorphized }}$ can be ascribed to variations in the

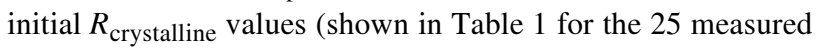
cells) due to the random arrangement of the grains in the cells [30], to variations in the shape of the amorphous volumes within the dog-bone-shaped line cells, to slightly different numbers and amplitudes of the applied initial reset pulse(s), which might have amorphized the cell either with a single pulse 

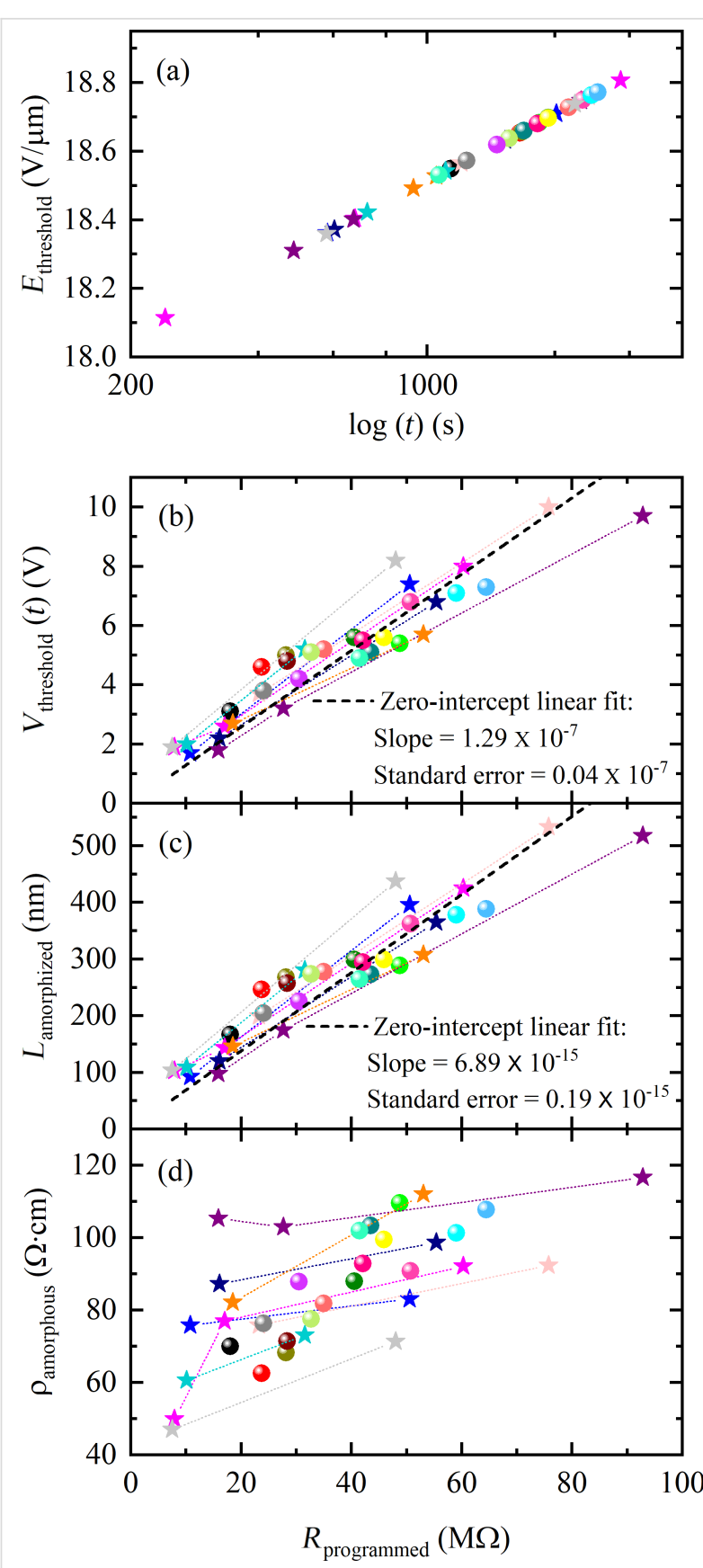

Figure 7: (a) Logarithmic upward drift of the threshold field $E_{\text {threshold }}(t)$ for 25 identical cells $[20,29]$ as a function of the elapsed time after amorphization $t$. (b) Measured threshold voltage $V_{\text {threshold }}(t)$ as a function of the measured $R_{\text {programmed. }}$ (c) Calculated $L_{\text {amorphized }}$ values as a function of the measured $R_{\text {programmed }}$ values, and (d) calculated $\rho_{\text {amorphous }}\left(10 \mathrm{~s}\right.$ ) values as a function of the measured $R_{\text {programmed }}$ values. The data points for different cells are plotted with different colors. Cells that demonstrated multiple re-amorphization events are plotted with stars connected with dotted lines ( 8 out of 25 cells) and the ones experiencing a single re-amorphization event are plotted with spheres ( 17 out of 25 cells).

or with multiple pulses in a more gradual manner, to the random arrangement of any voids created after every reset operation (Figure 8) [31], and to the variable amorphous resistance drift

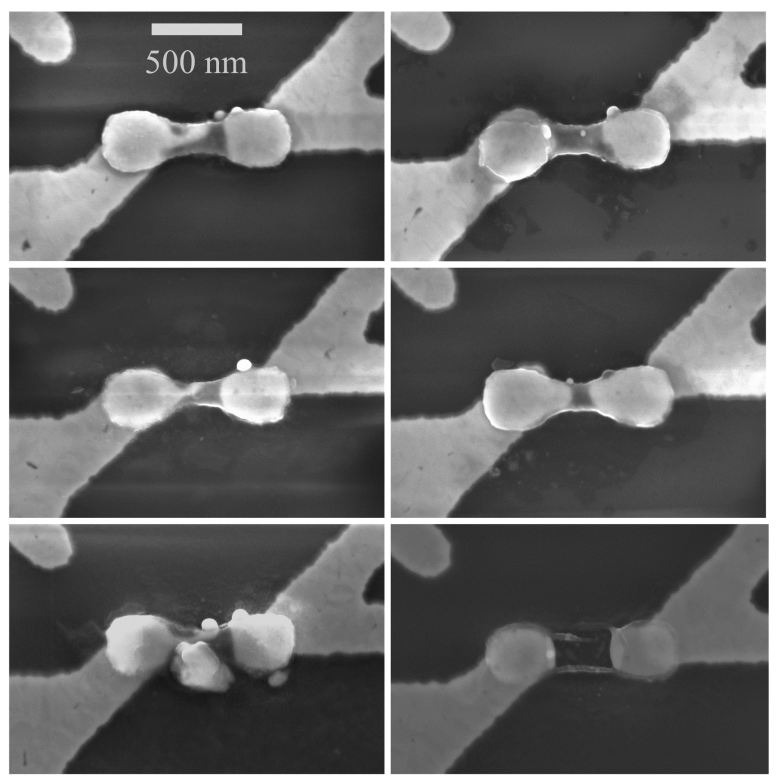

Figure 8: Representative SEM images of six physically broken cells with lost connections, showing significant variability in the void formation despite having similar dimension $\left(L_{\mathrm{GST}} \approx 470 \mathrm{~nm}\right.$,

$W_{\mathrm{GST}} \approx 130 \mathrm{~nm}$, and $t_{\mathrm{GST}} \approx 50 \mathrm{~nm}$ ) and being programmed to a similar initial $R_{\text {programmed. }}$

[32] of different cells during the elapsed times between the amorphization and threshold switching.

Understanding the physical origins and detailed properties of these sources of variability in $L_{\text {amorphized }}$ can contribute to the design of stronger hardware security primitives.

Assuming an ideal uniform cross section of the amorphous regions covering the entire cross-section area $A_{\text {amorphous }}=$ $W_{\mathrm{GST}} \times t_{\mathrm{GST}}\left(W_{G S T} \approx 130 \mathrm{~nm}, t_{\mathrm{GST}} \approx 50 \mathrm{~nm}\right)$, the amorphous resistivity at approx. $10 \mathrm{~s}$ after amorphization, $\rho_{\text {amorphous }}(10 \mathrm{~s})$, can be calculated using the extracted $L_{\text {amorphized }}$ and the drifted $R_{\text {programmed }}(10 \mathrm{~s})$ :

$$
\rho_{\text {amorphous }}(10 \mathrm{~s})=\frac{W \times t}{\left(\frac{L_{\text {amorphized }}}{R_{\text {programmed }}(10 \mathrm{~s})}\right)}
$$

$=\frac{130 \times 10^{-9} \mathrm{~m} \times 50 \times 10^{-9} \mathrm{~m}}{(6.90 \pm 0.19) \times 10^{-15} \mathrm{~m} \cdot \Omega^{-1}}=94.27 \pm 2.60 \Omega \cdot \mathrm{cm}$.

The calculated $\rho_{\text {amorphous }}(10 \mathrm{~s})$ is plotted as a function of the

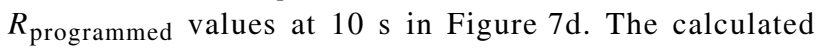
$\rho_{\text {amorphous }}(10 \mathrm{~s})$ of approx. $94 \Omega \cdot \mathrm{cm}$ is consistent with our earlier reported value of approx. $148 \Omega \cdot \mathrm{cm}$ at approx. $60 \mathrm{~s}$ after amorphization obtained from line cells [24] and with $100 \Omega \cdot \mathrm{cm}$ reported by Jeyasingh et al. [22]. This close match validates the 
accuracy of the amorphized length estimation method used in this work.

It is important to note that the calculation of $\rho_{\text {amorphous }}(10 \mathrm{~s})$ uses extracted $L_{\text {amorphized }}$ values and values of $R_{\text {programmed }}$ at $10 \mathrm{~s}$ measured under low field ( -0.1 to $+0.1 \mathrm{~V}$ DC sweep) after the post-reset pulse was applied. Hence, $\rho_{\text {amorphous }}$ is a lowfield resistivity calculation. Sharper rise and fall times are expected to reduce the threshold voltage values due to additional parasitic currents originating from the experimental setup. Reduced parasitic capacitance values from the experimental setup would result in applied $V_{\text {ch1 }}$ voltage pulses with faster and smoother rising and falling edges and enable the $V_{\text {cell }}$ and $I_{\text {cell }}$ to closely resemble the applied $V_{\mathrm{ch} 1}$ and the $I_{\mathrm{R} \_ \text {load }}$, respectively (Equations 4-7) with lesser distortion.

\section{Conclusion}

We propose a method to extract the amorphized length in phase-change memory devices based on electrical measurements. We utilized this procedure to study the variability in amorphized length values in 25 amorphized GST line cells of identical dimensions. Each cell was initially programmed to a similar amorphous resistance level (8-65 M $\Omega$ ) and then tested with a sequence of post-reset pulses of gradually increasing amplitude, separated by low-amplitude read DC sweeps. When the post-reset pulse amplitude is sufficient, a given cell undergoes threshold switching, melting and quenching and is re-amorphized, as inferred by the measurement and circuit simulation results. The process is continued until the cell breaks, in order to observe as many re-amorphization events as possible.

Each re-amorphization event is observed as a sudden increase in current during the pulse and a higher resistance after pulse, corresponding to a larger effective amorphized volume. The sharp increase in cell current is attributed to the parasitic capacitive current and thermal runaway in amorphous GST. The re-amorphization to increasingly higher resistance levels is also due to the sharp capacitive discharge current at the end of the postreset pulse.

Using the measured threshold voltage, and calculating an effective drifted threshold field at that switching time, we extracted the length of the amorphized region that experienced threshold switching, for each re-amorphization event, and related it with its previous resistance level. We observe a generally linear relation, but with a significant spread between the amorphized length and the programmed resistance. The amorphous resistivity calculated using the extracted amorphized length and the drifted programmed resistance is approx. $94 \Omega \cdot \mathrm{cm}$, within the range of previously reported values for melt-quenched GST, validating the accuracy of the amorphized length estimation method used in this paper.

The variability in the calculated amorphized length values, based on the measured threshold voltage values, can be attributed to different physical mechanisms, such as the variable amorphous resistance drift and cycling history, the unique amorphous volumes formed, and different crystalline and amorphous initial conditions. SEM images of physically broken cells captured after the electrical measurements show the randomness in the distribution of voids formed during recurrent reset operations, indicating another important factor for the observed variability. Combining these different physical sources of intrinsic variability in cell-to-cell and cycle-to-cycle operations, PCM devices can offer a promising platform for hardware security primitives, in which numerous origins of variability are well-desired features.

\section{Acknowledgements}

N. N. was responsible for electrical measurements, SEM imaging, data analysis, and the overall conception of the idea and writing of the manuscript. S. M. and R. S. K. automatized the electrical measurements. A. G. provided technical support by reproducing some electrical measurements. H. S. supervised the overall work and worked on the preparation of the manuscript.

The facilities at UConn-Thermo Fisher Scientific Center at the University of Connecticut were used for the SEM images. The devices were fabricated at IBM Watson Research Center under a joint study agreement with the University of Connecticut. We thank Dr. Faruk Dirisaglik, Dr. Adam Cywar, Dr. Chung Lam, and Dr. Yu Zhu for their support in device fabrication, and Professor Ali Gokirmak at the University of Connecticut for valuable discussions.

\section{Funding}

This research is funded by the multi-university research initiative (MURI) of Air Force Office of Scientific Research (AFOSR) under the grant FA9550-14-1-0351Z. A. G. was supported by U. S. National Science Foundation under the research experience for undergraduate (REU) award ECCS 1150960.

\section{ORCID ${ }^{\circledR}$ iDs}

Nafisa Noor - https://orcid.org/0000-0002-8559-2425

Anna Gorbenko - https://orcid.org/0000-0002-9850-7912

Helena Silva - https://orcid.org/0000-0001-6356-5402

\section{Preprint}

A non-peer-reviewed version of this article has been previously published as a preprint: https://doi.org/10.3762/bxiv.2020.58.v1 


\section{References}

1. Burr, G. W.; Breitwisch, M. J.; Franceschini, M.; Garetto, D.; Gopalakrishnan, K.; Jackson, B.; Kurdi, B.; Lam, C.; Lastras, L. A.; Padilla, A.; Rajendran, B.; Raoux, S.; Shenoy, R. S. J. Vac. Sci. Technol., B: Microelectron. Nanometer Struct.-Process., M eas., Phenom. 2010, 28, 223-262. doi:10.1116/1.3301579

2. Zhang, L.; Kong, Z. H.; Chang, C.-H.; Cabrini, A.; Torelli, G. IEEE Trans. Inf. Forensics Secur. 2014, 9, 921-932. doi:10.1109/tifs.2014.2315743

3. Noor, N.; Silva, H. Phase Change Memory for Physical Unclonable Functions. In Applications of Emerging Memory Technology; Suri, M., Ed.; Springer Verlag: Singapore, 2020; Vol. 63, pp 59-91. doi:10.1007/978-981-13-8379-3_3

4. Khan, R. S.; Noor, N.; Jin, C.; Scoggin, J.; Woods, Z.; Muneer, S.; Ciardullo, A.; Nguyen, P. H.; Gokirmak, A.; van Dijk, M.; Silva, H. Phase Change Memory and Its Applications in Hardware Security. In Security Opportunities in Nano Devices and Emerging Technologies; Tehranipoor, M.; Forte, D.; Rose, G. S.; Bhunia, S., Eds.; CRC Press: Boca Raton, FL, USA, 2017; pp 93-114. doi:10.1201/9781315265056-6

5. Noor, N. Exploiting Phase Change Memory Nano-Device Properties for Hardware Security Applications. Ph.D. Thesis, Department of Electrical and Computer Engineering, University of Connecticut, Storrs, CT, USA, 2019.

6. Noor, N.; Muneer, S.; Khan, R. S.; Gokirmak, A.; Silva, H. Enhanced Reset Variability in Phase Change Memory for Hardware Security Applications. In Bulletin of the American Physical Society, March 4-8, 2019; American Physical Society (APS): Boston, MA, USA; pp $1610 \mathrm{ff}$. https://meetings.aps.org/Meeting/MAR19/Session/K33.8

7. Noor, N.; Muneer, S.; Adnane, L.; Khan, R. S.; Gorbenko, A.; Dirisaglik, F.; Cywar, A.; Lam, C.; Zhu, Y.; Gokirmak, A.; Silva, H. Utilizing Programming Variability in Phase Change Memory Cells for Security. In 2017 Material Research Society (MRS) Fall Meeting \& Exhibit, Nov 26-Dec 1, 2017; Materials Research Society: Boston, MA, USA.

https://www.researchgate.net/publication/326129144

8. Santala, M. K.; Raoux, S.; Topuria, T.; Reed, B. W.; LaGrange, T.; Campbell, G. H. Thin Solid Films 2014, 571, 39-44. doi:10.1016/j.tsf.2014.09.063

9. Tripathi, S.; Janish, M.; Dirisaglik, F.; Cywar, A.; Zhu, Y.; Jungjohann, K.; Silva, H.; Carter, C. B. Microsc. Microanal. 2018, 24 , 1904-1905. doi:10.1017/s1431927618010000

10. Tripathi, S.; Janish, M.; Noor, N.; Kotula, P.; Pete, D.; Jungjohann, K.; Silva, H.; Carter, B. PCM Materials \& Devices: In-Situ TEM Imaging. In CINT User's Meeting, Sept 24-25, 2018; Sandia National Lab: Albuquerque, NM, USA. https://www.osti.gov/servlets/purl/1567827

11. Warren, A. C. IEEE Trans. Electron Devices 1973, 20, 123-131. doi:10.1109/t-ed.1973.17618

12. Adler, D.; Henisch, H. K.; Mott, S. N. Rev. Mod. Phys. 1978, 50, 209-220. doi:10.1103/revmodphys.50.209

13. Owen, A. E.; Robertson, J. M. IEEE Trans. Electron Devices 1973, 20 , 105-122. doi:10.1109/t-ed.1973.17617

14. lelmini, D.; Zhang, Y. J. Appl. Phys. 2007, 102, 054517. doi:10.1063/1.2773688

15. Jacoboni, C.; Piccinini, E.; Buscemi, F.; Cappelli, A. Solid-State Electron. 2013, 84, 90-95. doi:10.1016/j.sse.2013.02.007
16. Jandieri, K.; Rubel, O.; Baranovskii, S. D.; Reznik, A.; Rowlands, J. A.; Kasap, S. O. Phys. Status Solidi C 2008, 5, 796-799. doi:10.1002/pssc.200777565

17. Krebs, D.; Raoux, S.; Rettner, C. T.; Burr, G. W.; Salinga, M.; Wuttig, M. Appl. Phys. Lett. 2009, 95, 082101. doi:10.1063/1.3210792

18. Wimmer, M.; Salinga, M. New J. Phys. 2014, 16, 113044. doi:10.1088/1367-2630/16/11/113044

19. Le Gallo, M.; Athmanathan, A.; Krebs, D.; Sebastian, A. J. Appl. Phys. 2016, 119, 025704. doi:10.1063/1.4938532

20. Karpov, I. V.; Mitra, M.; Kau, D.; Spadini, G.; Kryukov, Y. A.; Karpov, V. G. J. Appl. Phys. 2007, 102, 124503. doi:10.1063/1.2825650

21. lelmini, D.; Lavizzari, S.; Sharma, D.; Lacaita, A. L. Physical Interpretation, Modeling and Impact on Phase Change Memory (PCM) Reliability of Resistance Drift Due to Chalcogenide Structural Relaxation. In 2007 IEEE International Electron Devices Meeting, Washington, DC, USA; 2007; pp 939-942. doi:10.1109/iedm.2007.4419107

22. Jeyasingh, R. G. D.; Kuzum, D.; Wong, H.-S. P. IEEE Trans. Electron Devices 2011, 58, 4370-4376. doi:10.1109/ted.2011.2169798

23. Kim, S.; Lee, B.; Asheghi, M.; Hurkx, F.; Reifenberg, J. P.; Goodson, K. E.; Wong, H.-S. P. IEEE Trans. Electron Devices 2011, 58, 584-592. doi:10.1109/ted.2010.2095502

24. Dirisaglik, F. High-Temperature Electrical Characterization of $\mathrm{Ge}_{2} \mathrm{Sb}_{2} \mathrm{Te}_{5}$ Phase Change Memory Devices. Ph.D. Thesis, Department of Electrical and Computer Engineering, University of Connecticut, Storrs, CT, USA, 2014.

25. Dirisaglik, F.; Bakan, G.; Jurado, Z.; Muneer, S.; Akbulut, M.; Rarey, J.; Sullivan, L.; Wennberg, M.; King, A.; Zhang, L.; Nowak, R.; Lam, C.; Silva, H.; Gokirmak, A. Nanoscale 2015, 7, 16625-16630. doi:10.1039/c5nr05512a

26. Adnane, L.; Dirisaglik, F.; Cywar, A.; Cil, K.; Zhu, Y.; Lam, C.; Anwar, A. F. M.; Gokirmak, A.; Silva, H. J. Appl. Phys. 2017, 122, 125104. doi:10.1063/1.4996218

27. Bakan, G.; Cywar, A.; Silva, H.; Gokirmak, A. Appl. Phys. Lett. 2009, 94, 251910. doi:10.1063/1.3159877

28. lelmini, D.; Mantegazza, D.; Lacaita, A. L.; Pirovano, A.; Pellizzer, F. IEEE Electron Device Lett. 2005, 26, 799-801. doi:10.1109/led.2005.857719

29. Lankhorst, M. H. R.; Ketelaars, B. W. S. M. M.; Wolters, R. A. M. Nat. Mater. 2005, 4, 347-352. doi:10.1038/nmat1350

30. Woods, Z.; Scoggin, J.; Cywar, A.; Adnane, L.; Gokirmak, A. IEEE Trans. Electron Devices 2017, 64, 4472-4478. doi:10.1109/ted.2017.2745500

31. Cywar, A. D. Melting and Crystallization of $\mathrm{Si}$ and $\mathrm{Ge}_{2} \mathrm{Sb}_{2} \mathrm{Te}_{5}$ Nanostructures. Ph.D. Thesis, Department of Electrical and Computer Engineering, University of Connecticut, Storrs, CT, USA, 2016.

32. Boniardi, M.; Ielmini, D.; Lavizzari, S.; Lacaita, A. L.; Redaelli, A.; Pirovano, A. IEEE Trans. Electron Devices 2010, 57, 2690-2696. doi:10.1109/ted.2010.2058771 


\section{License and Terms}

This is an Open Access article under the terms of the Creative Commons Attribution License (https://creativecommons.org/licenses/by/4.0). Please note that the reuse, redistribution and reproduction in particular requires that the authors and source are credited.

The license is subject to the Beilstein Journal of Nanotechnology terms and conditions: (https://www.beilstein-journals.org/bjnano)

The definitive version of this article is the electronic one which can be found at:

https://doi.org/10.3762/bjnano.11.147 